\title{
PENELITIAN PENAMBAHAN BAHAN ADITIF KAPUR PADAM SEBAGAI BAHAN PENGISI FILLER PADA CAMPURAN ASPAL BETON
}

\author{
${ }^{1 *}$ Candra Yulianto, ${ }^{2}$ Yosef Cahyo, ${ }^{3}$ Ahmad Ridwan, ${ }^{4}$ Agata Iwan Candra \\ Fakultas Teknik Universitas Kadiri \\ email: ${ }^{1 *}$ cacangyuli@gmail.com,${ }^{2}$ yosef.cs@unik-kediri.ac.id, ${ }^{3}$ ahmad_ridwan@unik- \\ kediri.ac.id, ${ }^{4}$ iwan_candra@unik-kediri.ac.id
}

\begin{abstract}
In the construction of highways, people generally often use concrete asphalt as material for road construction. Asphalt concrete mix (Hotmix) usage in Indonesia from year to year is higher. The coefficient of production of asphalt concrete (hotmix) can be made from locally available materials and has good weather resistance. The purpose of this study is how to influence the addition of extinguished lime to the mixture on asphalt concrete (hotmix) and Know what percentage of the extinguished lime mixture to reach the optimum point of asphalt concrete. From the calculation results it can be concluded from the addition of $5 \%, 10 \%$, and $15 \%$ in the stability value of $778 \mathrm{Kg}, 645 \mathrm{Kg}, 534 \mathrm{Kg}$; VIM of $8.17 \%, 7.51 \%$ and $6.85 \%$; VMA of $19.87 \%, 18.55 \%$ and $17.73 \%$; VFB of $58.88 \%$, $56.61 \%$ and $54.35 \%$; $M Q$ of $297 \mathrm{Kg} / \mathrm{mm}, 230 \mathrm{Kg}$ $/ \mathrm{mm}$, and $198 \mathrm{Kg} / \mathrm{mm}$.
\end{abstract}

Keywords $\quad$ : Concrete Asphalt, Hydrated Lime, Marshall Test, Filler

\begin{abstract}
Abstrak
Pada konstruksi jalan raya masyarakat umumnya sering menggunakan Aspal beton sebagai bahan pembuatan konstruksi jalan raya. campuran aspal beton(Hotmix) penggunaannya di Indonesia dari tahun ke tahun makin tinggi. Koefisien produksi aspal beton(hotmix) dapat dibuat dari bahan- bahan lokal yang tersedia dan memiliki ketahanan yang baik terhadap berbagai cuaca. Tujuan dari penelitian ini adalah bagaimana pengaruh penambahan kapur padam pada bahan campuran pada aspal beton(hotmix) dan Mengetahui berapa persentase campuran kapur padam untuk mencapai titik optimum aspal beton. Dari hasil perhitungan dapat disimpulkan dari penambahan 5\%, 10\%, dan 15\% pada Nilai stabilitas sebesar 778 $\mathrm{Kg}, 645 \mathrm{Kg}, 534 \mathrm{Kg}$; VIM sebesar 8.17\%, 7.51\%, dan 6.85\%; VMA sebesar $19.87 \%$, 18.55 \%, dan 17.73 $\%$; VFB sebesar 58.88\%, 56.61\%, dan 54.35\%; MQ sebesar $297 \mathrm{Kg} / \mathrm{mm}, 230 \mathrm{Kg} / \mathrm{mm}$, dan $198 \mathrm{Kg} / \mathrm{mm}$.
\end{abstract}

Kata Kunci : Aspal Beton, Kapur Padam, Marshall Test, Filler 


\section{PENDAHULUAN}

Pada konstruksi jalan raya masyarakat umumnya sering menggunakan Aspal beton sebagai bahan pembuatan konstruksi jalan raya. campuran aspal beton (Hotmix) penggunaannya di Indonesia dari tahun ke tahun makin tinggi[1][2][3]. Dikarenakan aspal beton (Hotmix) mempunyai kelebihan dibanding dengan bahan lainnya, Misalnya harganya yang relatif ekonomis/murah dibanding menggunakan beton, keunggulannya pada beban berat kendaraan yang tinggi. Keefisienan produksi aspal beton (hotmix) dapat dibuat dari bahan-bahan lokal yang tersedia dan memiliki ketahanan yang baik terhadap berbagai cuaca [4][5]. Kekuatan utama aspal beton ada pada agregat yang saling mengunci dan sedikit pada pasir/ filler/ bitumen sebagai mortar[6][7]. Di samping kecukupan workability (sifat kemudahan untuk pekerjaan) ada Tujuh sifat dasar aspal beton yang harus diperhatikan dalam pembuatan campuran aspal beton, yaitu:

1. Stabilitas

2. Durabilitas (keawetan)

3. Fleksibilitas (kelenturan)

4. Tahanan geser (skid resistance).

5. Kedap air

6. Kemudahanpekerjaan (workability)

7. Ketahanan kelelehan (fatique resistance)

Ketujuh sifat di atas harus mencapai titik optimum untuk bisa dikatakan layak dalam campuran aspal beton.Bahan pengisi dalam campuran aspal beton(hotmix) adalah bahan harus lolos saringan No.200 (0,075 mm)[8][9][10]. Macam bahan pengisi yang dapat digunakan ialah: abu batu, kapur padam, portland cement (PC), debu dolomite, abu terbang, debu tanur tinggi pembuat. Banyaknya bahan pengisi dalam campuran aspal beton sangat dibatasi[11][12]. Kebanyakan bahan pengisi,maka campuran akan sangat kaku dan mudah retak selain itu memerlukan aspal yang banyak untuk memenuhi workability[13][14]. Sebaliknya jika kekurangan bahan pengisi campuran menjadi sangat lentur dan mudah terdeformasi oleh roda kendaraan sehingga menghasilkan jalan yang bergelombang[15][16][17]. Pada penelitian ini bahan pengisi dibatasi antara $2 \%$ hingga $8 \%$ dari berat total campuran aspal beton[18][19][20].

\section{METODOLOGI PENELITIAN}

\subsection{Data Umum}

Dalam pelaksanaan dan penyusunan laporan tugas akhir penulis melakukan pengamatan tentang Penambahan Bahan Adiktif Kapur Hidrat Kapur Padam Sebagai Bahan Pengisi Filler Pada 
Campuran Aspal Beton. Pemeriksaan ini dilakukan di laboratorium Teknik Sipil Universitas Kadiri, dengan hasil yang terdapat di bawah ini : Bahan Penelitian.

Dalam penelitian ini bahan - bahan yang diperlukan adalah:

a. Kapur padam yang dibeli di toko bangunan di daerah Kediri

b. Pasir bladak yang dibeli dari galangan pasir bladak blitar

c. Koral dibeli dari toko banguan di daerah Kediri

d. Asphalt berasal dari Pertamina

Pengumpulan Material

1. Persiapan Benda Uji

Persiapan benda uji dengan pengayakan benda uji agregat kasar dan halus dengan ayakan yang telah di tentukan Pengeringan agregat pada suhu 105 ' $\mathrm{C}[21][22]$.

2. Penentuan Suhu Pencampuran dan Pemadatan

\subsection{Persiapan JMF (Job Mix Formula)}

Dalam penelitian kali ini mengunakan JMF (Job Mix Formula) yang sudah ada[23].

Tabel 1. Proporsi Campuran Agregat Pada Laston /AC-(L).

\begin{tabular}{|c|c|cc|cc|cc|}
\hline No & Bahan & \multicolumn{2}{|c|}{ Jumlah\% } & \multicolumn{2}{|c|}{ Individual } & \multicolumn{2}{|c|}{ Comulative } \\
\hline 1 & Agragat Kasar & 25 & $\%$ & 300 & gram & 300 & gram \\
\hline 2 & Agragat Medium & 33 & $\%$ & 396 & gram & 696 & gram \\
\hline 3 & Agragat Halus & 40 & $\%$ & 480 & gram & 1176 & gram \\
\hline 4 & Filler & 2 & $\%$ & 24 & gram & 1200 & gram \\
\hline
\end{tabular}

Sumber: (Data (JMF) Job Mix Formula Acuan)

Tabel 2. Penyesuaian Proporsi Campuran Laston/AC-(L)

\begin{tabular}{|c|c|cc|cc|cc|}
\hline No & Bahan & \multicolumn{2}{|c|}{ Jumlah $\%$} & \multicolumn{2}{|c|}{ Individual } & \multicolumn{2}{c|}{ Comulative } \\
\hline 1 & Agragat Kasar & 23.43 & $\%$ & 281 & gram & 281.2 & gram \\
\hline 2 & Agragat Medium & 30.92 & $\%$ & 371 & gram & 652.2 & gram \\
\hline 3 & Agragat Halus & 37.48 & $\%$ & 450 & gram & 1102 & gram \\
\hline 4 & Filler & 1.87 & $\%$ & 22 & gram & 1124 & gram \\
\hline 5 & Aspal & 6.3 & $\%$ & 76 & gram & 1200 & gram \\
\hline
\end{tabular}

Sumber: (Data (JMF) Job Mix Formula Acuan) 


\section{HASIL DAN PEMBAHASAN}

\subsection{Hasil Pemeriksaan Karakteristik Aspal}

Pada Bab IV ini akan membahas Penelitian Penambahan Bahan Adiktif Kapur Hidrat (Kapur Padam) Sebagai Bahan Pengisi (Filler) Pada Campuran Aspal Beton. Pemeriksaan ini dilakukan di laboratorium Teknik Sipil Universitas Kadiri, dengan hasil yang terdapat di bawah ini: Hasil pengujian karakteristik aspal minyak menggunakan metode SNI dapat melihat tabel 3.

\subsubsection{Gradasi agregat beton aspal}

Gradasi agregat adalah susunan butir agregat sesuai ukurannya. Ukuran butir dapat diperoleh melalui pemeriksaan analisa saringan.Gradasi agregat dinyatakan dalam presentase lolos atau tertahan,yang dihitung berdasarkan berat agregat.

Tabel 3. Karakteristik Aspal Minyak Menggunakan Metode SNI

\begin{tabular}{|c|c|c|c|c|c|}
\hline \multirow{2}{*}{ No } & Pengujian & \multirow{2}{*}{ hasil } & \multicolumn{2}{|c|}{ spesifikasi } & \multirow{2}{*}{ satuan } \\
& & & Min. & Max. & \\
\hline 1 & $\begin{array}{c}\text { Penetrasi } 25^{\circ} \text { Sebelum } \\
\text { kehilangan berat }\end{array}$ & 65 & 60 & 79 & $0,1 \mathrm{~mm}$ \\
\hline 2 & Titik Lembek & 52 & 48 & 58 & ${ }^{\circ} \mathrm{C}$ \\
\hline 3 & Daktilitas pada $25^{\circ} \mathrm{C}$ & 115 & 100 & - & $\mathrm{Cm}$ \\
\hline 4 & Titik nyala & 320 & 200 & - & ${ }^{\circ} \mathrm{C}$ \\
\hline 5 & Berat Jenis & 1,01 & 1 & - & \\
\hline 6 & Kehilangan Berat & 0,2 & - & 0,8 & $\%$ \\
\hline 7 & $\begin{array}{c}\text { Penetrasi 25 Setelah } \\
\text { kehilangan berat }\end{array}$ & 85 & 54 & - & $0,1 \mathrm{~mm}$ \\
\hline
\end{tabular}

Sumber: Pedoman SNI Perkerasan Jalan Raya

Tabel 4. Persyaratan Gradasi Agregat Campuran Beton Aspal (AC)

\begin{tabular}{cccccccc}
\hline \multicolumn{2}{c}{ Ukuran Ayakan } & \multicolumn{7}{c}{ \% Berat yang Lolos } \\
\hline \multirow{2}{*}{ ASTM } & \multirow{2}{*}{$\mathbf{m m})$} & \multicolumn{7}{c}{ Gradasi Halus } & \multicolumn{3}{c}{ Gradasi Kasar } \\
\cline { 3 - 8 } & AC-WC & AC-BC & AC-Base & AC-WC & AC-BC & AC-Base \\
\hline $11^{1 / 2}$ & 3,750 & - & - & 100 & - & - & 100 \\
$1^{\prime \prime}$ & 25,000 & - & 100 & $90-100$ & - & 100 & $90-100$ \\
$3 / 4^{\prime \prime}$ & 19,000 & 100 & $90-100$ & $73-90$ & 100 & $90-100$ & $73-90$ \\
$1 / 2 "$ & 12,500 & $90-100$ & $74-90$ & $61-79$ & $90-100$ & $71-90$ & $55-76$ \\
$3 / 8^{\prime \prime}$ & 9,500 & $72-90$ & $64-82$ & $47-67$ & $72-90$ & $58-80$ & $45-66$ \\
No. 4 & 4,750 & $54-69$ & $47-64$ & $39,5-50$ & $43-63$ & $37-56$ & $28-39,5$ \\
No. 8 & 2,360 & $39,1-53$ & $34,6-49$ & $30,8-37$ & $28,3-39,1$ & $23-34,6$ & $19-26,8$ \\
No. 16 & 1,180 & $31,6-40$ & $28,3-38$ & $24,1-28$ & $19-25,6$ & $15-22,3$ & $12-18,1$ \\
No. 30 & 0,600 & $23,1-30$ & $20,7-28$ & $17,6-22$ & $13-19,1$ & $10-16,7$ & $7-13,6$ \\
No. 50 & 0,300 & $15,5-22$ & $13,7-20$ & $11,4-16$ & $9-15,5$ & $7-13,7$ & $5-11,4$ \\
No. 100 & 0,1500 & $9-15$ & $4-13$ & $4-10$ & $6-13$ & $5-11$ & $4,5-9$ \\
No. 200 & 0,075 & $4-10$ & $4-8$ & $3-6$ & $4-10$ & $4-8$ & $3-7$ \\
\hline
\end{tabular}

Sumber : Departemen Pekerjaan Umum, 2010 
Tabel 5. Ketentuan Sifat-Sifat Perkerasan Beton

\begin{tabular}{|c|c|c|c|c|}
\hline \multirow{2}{*}{\multicolumn{2}{|c|}{ Sifat - sifat Campuran }} & \multicolumn{3}{|c|}{ Laston } \\
\hline & & WC & BC & Base \\
\hline $\begin{array}{l}\text { Penyerapan Aspal (\%) } \\
\text { jumlah tumbukan per bidang }\end{array}$ & Maks & \multicolumn{3}{|c|}{1,2} \\
\hline \multirow{2}{*}{ Rongga dalam campuran (\%) } & Min & \multicolumn{2}{|c|}{3,5} & \multirow{2}{*}{112} \\
\hline & Maks. & \multicolumn{2}{|c|}{5,0} & \\
\hline Rongga dalam agregat (VMA) $(\%)$ & Min & 15 & 14 & 13 \\
\hline Rongga terisi aspal (\%) & Min & 65 & 63 & 60 \\
\hline \multirow{2}{*}{ Stabilitas Marshall (kg) } & Min & \multicolumn{2}{|c|}{800} & 1800 \\
\hline & Maks & & & - \\
\hline \multirow{2}{*}{ Kelelehan (mm) } & Min & & & 4,5 \\
\hline & Maks & & & $\because$ \\
\hline Marshall Quetient (kgmm) & Min & & & 300 \\
\hline $\begin{array}{l}\text { Stabilitas Marshall sisa (\%) setelah } \\
\text { Perendaman selama } 24 \mathrm{jam}, 60^{\circ} \mathrm{C}\end{array}$ & Min & \multicolumn{3}{|c|}{90} \\
\hline $\begin{array}{l}\text { Rongga dalam campuran }(\%) \text { pada } \\
\text { kepadatan membal (refusal)) }\end{array}$ & Min & \multicolumn{3}{|c|}{2,5} \\
\hline
\end{tabular}

Sumber : Departemen Pekeja an Umum, 2010

Tabel 6. Uji Karakteristik Marshall

\begin{tabular}{|c|c|c|c|c|c|c|c|}
\hline Gradasi & Campuran & & & & & & \\
\hline & Lolos & Tertahan & & & & & \\
\hline Saringan & $(\%)$ & $(\%)$ & & & & & \\
\hline $3 / 4 "$ & 100,00 & 0,00 & & & & 0,00 & $\mathrm{Gr}$ \\
\hline $1 / 2^{\prime \prime}$ & 93,00 & 7,00 & & & & 84,00 & $\mathrm{Gr}$ \\
\hline $3 / 8^{\prime \prime}$ & 83,00 & 12,00 & & & & 144,00 & $\mathrm{Gr}$ \\
\hline $4 "$ & 53,00 & 28,00 & & & & 335,00 & $\mathrm{Gr}$ \\
\hline $8 "$ & 33,55 & 19,45 & $\mathrm{CA}=$ & 66,08 & & 230,00 & $\mathrm{Gr}$ \\
\hline $16 "$ & 22,30 & 11,25 & & & & 137,00 & $\mathrm{Gr}$ \\
\hline $30 "$ & 16,05 & 6,25 & & & & 75,00 & $\mathrm{Gr}$ \\
\hline $50 "$ & 12,25 & 3,80 & & & & 45,00 & $\mathrm{Gr}$ \\
\hline $100 "$ & 9,50 & 2,75 & & & & 35,00 & $\mathrm{Gr}$ \\
\hline $200^{\prime \prime}$ & 7,00 & 2,50 & $\mathrm{FA}=$ & 26,92 & & 30,00 & $\mathrm{Gr}$ \\
\hline \multicolumn{2}{|c|}{ Filler $=$ Semen } & 7 & $\mathrm{~F}$ & 7 & & 85,00 & $\mathrm{Gr}$ \\
\hline \multicolumn{3}{|c|}{ Total Prosentase } & \multirow{2}{*}{\multicolumn{2}{|c|}{$\underline{100}$}} & & & \\
\hline \multicolumn{3}{|c|}{ Total Berat } & & & \multicolumn{2}{|l|}{1200} & $\mathrm{Gr}$ \\
\hline
\end{tabular}

Sumber: Pedoman SNI Perkerasan Jalan Raya

\subsubsection{Hasil pengujian karakteristik}

A. Marshall

Pengujian dengan masing masing variasi kandungan kadar aspal minyak menggunakan pemadat Marshall dengan jumlah tumbukan 75 kali untuk masing- masing bidang. Parameter yang didapatkan yaitu stabilitas dan kelenturan atau kelelehan (flow) yang 
menunjukkan ukuran ketahanan suatu benda uji dalam menerima beban diperoleh dari hasil analisis terhadap pengujian Marshall. Selain itu, nilai volumetric yang terdiri rongga di antara agregat(VMA), rongga terisi aspal (VFB), dan rongga dalam campuran (VIM) juga merupakan karakteristik Marshall. Tabel 7. memperlihatkan hasil pengujian karakteristik Marshall.

Tabel 7. Hasil pengujian karakteristik Marshall untuk seluruh parameter

\begin{tabular}{|c|c|c|c|c|c|c|c|c|}
\hline no & $\begin{array}{c}\text { Kadar } \\
\text { Aspal } \\
\%\end{array}$ & $\begin{array}{c}\text { Kadar } \\
\text { Kapur } \\
\text { padam } \\
\%\end{array}$ & $\begin{array}{c}\text { VMA } \\
\%\end{array}$ & $\begin{array}{c}\text { VIM } \\
\%\end{array}$ & $\begin{array}{c}\text { VFB } \\
\%\end{array}$ & Stabilitas & Flow & MQ \\
\hline 1 & $5.78 \%$ & $5 \%$ & 19.87 & 8.17 & 58.88 & 880 & 3,56 & 297 \\
\hline 2 & $5.78 \%$ & $10 \%$ & 18,55 & 7.51 & 56.61 & 775 & 3,1 & 230 \\
\hline 3 & $5.78 \%$ & $15 \%$ & 17.73 & 6.85 & 54.35 & 675 & 2,76 & 198 \\
\hline 4 & \multicolumn{2}{|c|}{ spesifikasi } & $\begin{array}{c}15 \% \\
<\end{array}$ & $3-5 \%$ & $\begin{array}{c}65 \% \\
<\end{array}$ & $800 \mathrm{Kg}$ & $2-4 \mathrm{~mm}$ & Min250 \\
\hline
\end{tabular}

Sumber: Pengolahan Data Uji Laboratorium

B. Hubungan Kadar Aspal Minyak Dengan VIM (Void In Mix)

Rongga udara dalam campuran atau VIM dalam campuran perkerasan beraspal terdiri atas ruang udara diantara partikel agregat yang terselimuti aspal. VIM dinyatakan dalam persentase terhadap volume beton aspal padat. Berdasarkan hasil pengujian volumetrik, terlihat pada Grafik 1. hubungan antara kadar aspal minyak dengan nilai VIM. Nilai VIM yang dipersyaratkan oleh Spesifikasi Umum 2010, revisi 3 adalah sebesar 3\% sampai dengan 5\%. Terlihat pada kadar kapur padam 5\%, 10\%, dan $15 \%$ nilai VIM (Void in Mix) masing masing sebesar 8,17\%, 7,51\%, 6,85\% berdasarkan nilai VIM yang diperoleh terlihat bahwa nilai VIM yang masuk spesifikasi 2010 revisi 3 adalah kadar 5\% sedangkan kadar 10\% dan 15\% tidak memenuhi spesifikasi 2010, revisi 3. 


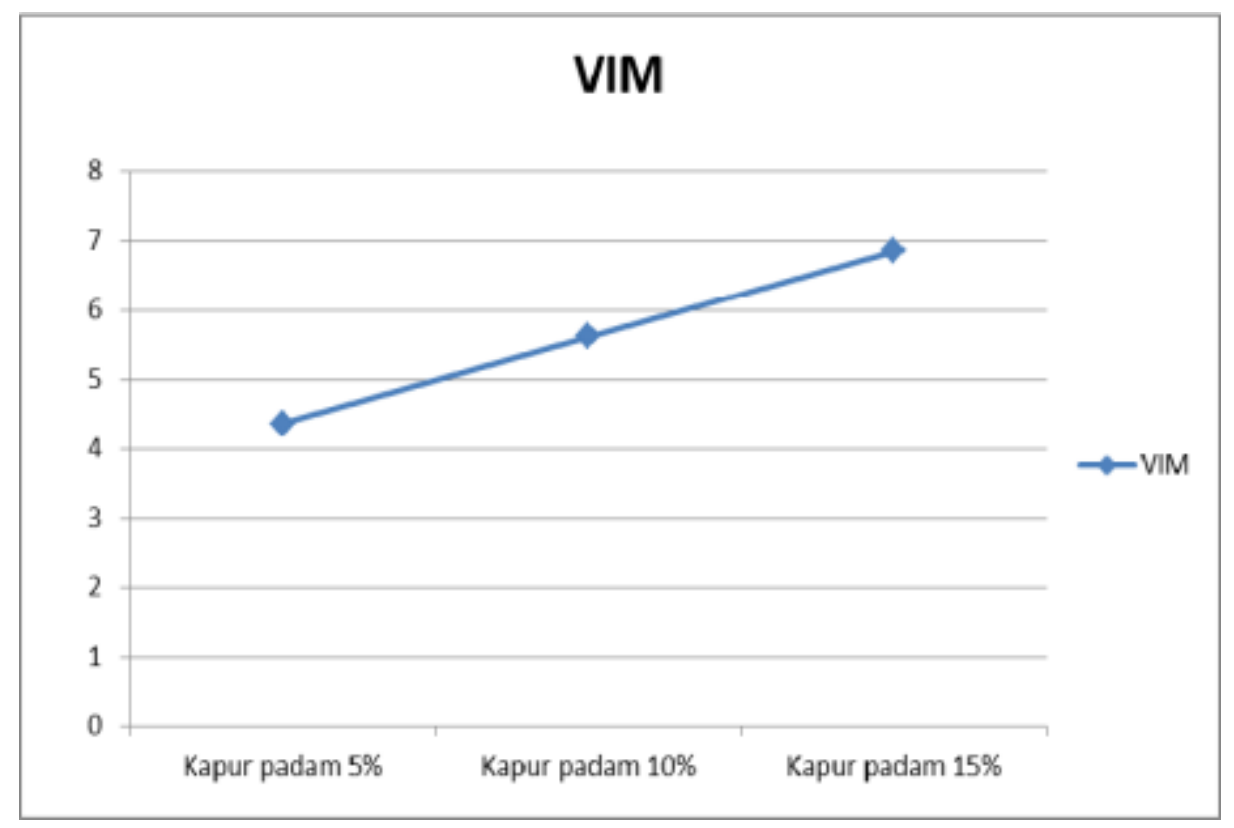

Grafik 1. Hubungan Antara Kadar Batu Kapur Padam Dengan Nilai VIM Sumber : Analisa Perhitungan

C. Hubungan Kadar Aspal Minyak Dengan VMA (Void Mineral Aggregate)

Rongga diantara mineral agregat (VMA) adalah celah rongga diantara agregat pada perkerasan beraspal, termasuk rongga udara dan volume aspal efektif (bukan volume aspal yang diserap agregat). VMA dihitung berdasarkan BJBulk(Gsb) agregat dapat dinyatakan sebagai persen volume Bulk campuran yang sudah dipadatkan. Spesifikasi umum 2010 Revisi 3 Divisi 6 tentang Perkerasan Aspal mensyaratkan bahwa nilai VMA dalam campuran beraspal adalahminimal 15\%. Grafik 2. memperlihatkan hubungan antara kadar kandungan kapur padam terhadap nilai VMA, dimana nilai VMA pada kadar kapur padam $5 \%, 10 \%, 15 \%$ adalah $19,87 \%, 18,55 \%$ dan $17,73 \%$. Dengan hasil seperti diatas dapat disimpulkan bahwa kadarkapur padam yang digunakan memenuhi spesifikasi yang telah di syaratkan oleh spesifikasi umum 2010, revisi 3, divisi 6 tentang perkerasan aspal. 


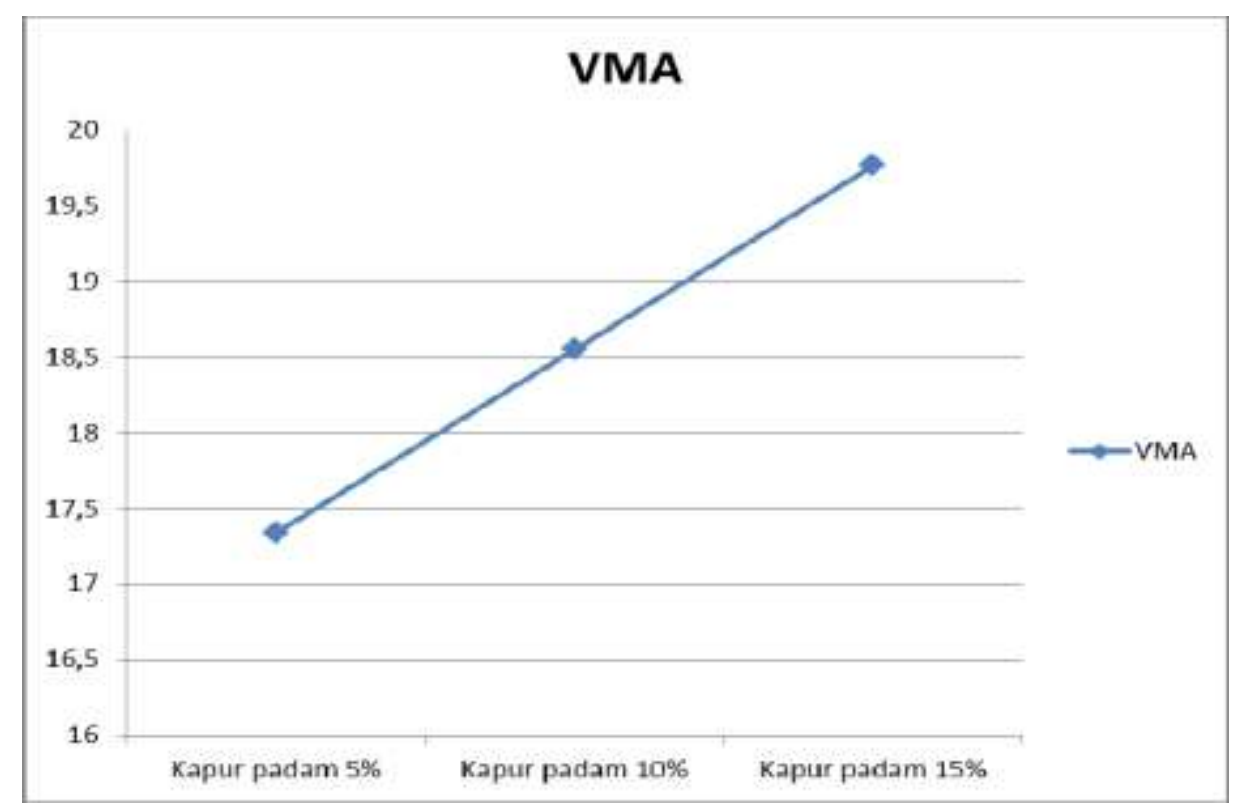

Grafik 2. Hubungan Antara Kadar Kapur Padam Terhadap Nilai VMA Sumber : Analisa Perhitungan

D. Hubungan Kadar Aspal Minyak Dengan VFB (Void Filled Bitumen)

Grafik 3. memperlihatkan hubungan kandungan kadar kapur padam dengan nilai VFB. Berdasarkan Spesifikasi umum 2010, Revisi 3, Divisi 6 tentang Perkerasan Aspal, persyaratan VFB dalam campuran beraspal adalah minimal 65\%. Hasil pengujian volumetrik campuran beraspal menggunakan kapur padam sebagai agregat dan aspal minyak sebagai bahan pengikat berupa parameter VFB memperlihatkan nilai sebesar $58,88 \%, 56,61 \%, 54,35 \%$ oleh karena itu, semua kapur padam memenuhi spesifikasi umum 2010, revisi 3 divisi 6 tentang perkerasan aspal kecuali kadar kapur padam 15\%.

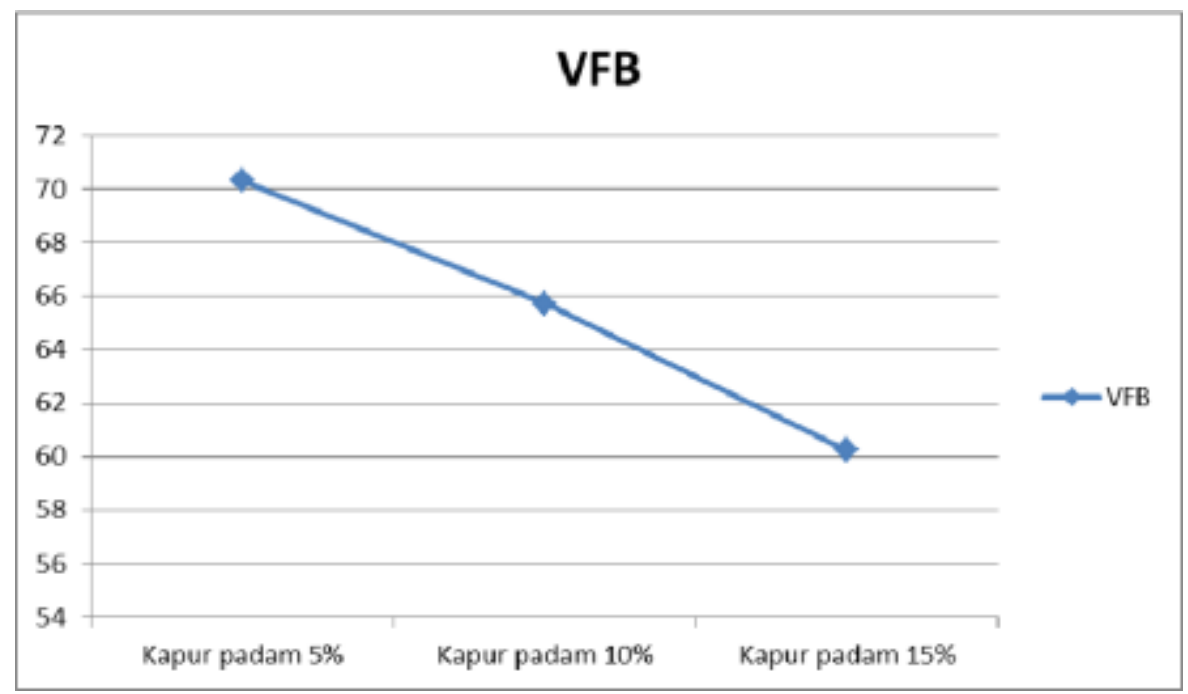

Grafik 3. Hubungan Kandungan Kadar Kapur Padam Dengan Nilai VFB Sumber : Analisa Perhitungan 
E. Hubungan Kadar Aspal Minyak dengan Stabilitas

Berdasarkan hasil pengujian Marshall,hubungan antara kadar kapurpadam dengan nilai stabilitas ditunjukkan dengan Grafik 4. Hasil pengujian memperlihatkan ketika kandungan kapurpadam menurun maka nilai stabilitas juga menurun hingga mencapai nilai minimum

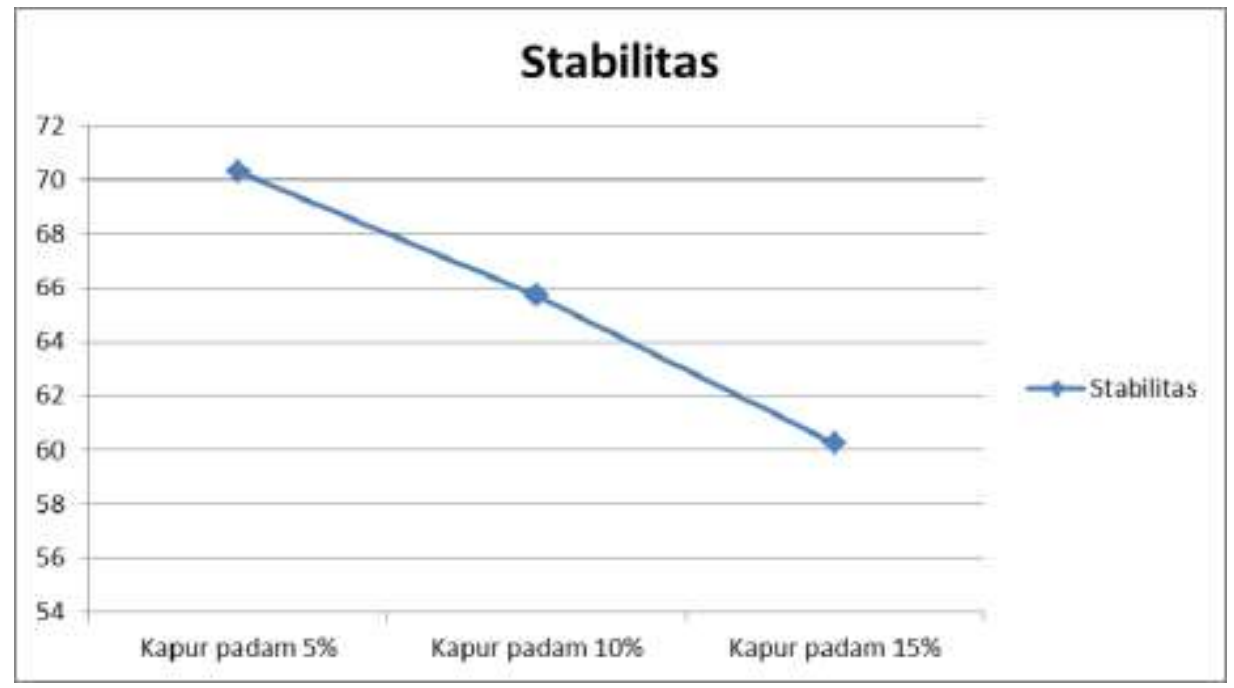

Grafik 4. Hubungan Antara Kadar Kapur Padam Terhadap Stabilitas

\section{Sumber : Analisa Perhitungan}

Berdasarkan grafik diatas nilai stabilitas didapat belum dikatakan memenuhi spesifikasi yang telah ditetapkan oleh 2010, revisi 3 binamarga yaitu sebesar $\geq 800 \mathrm{Kg}$.nilai stabilitas terendah diperoleh pada campuran kapur padam $15 \%$ yaitu $675 \mathrm{Kg}$ dan nilai stabilitas tertinggi terdapat pada campuran kapur padam 5\% yaitu sebesar $880 \mathrm{Kg}$. dengan ini dapat disimpulkan bahwa kapur padam yang optimum berkisar diantara 1-3\%.

F. Kadar kapur padam optimum dengan menggunakan Quotient Marshall Pada grafik dibawah ini dapat dilihat berapa kadar optimum kapur padam apabila digunakan untuk campuran aspal beton. 


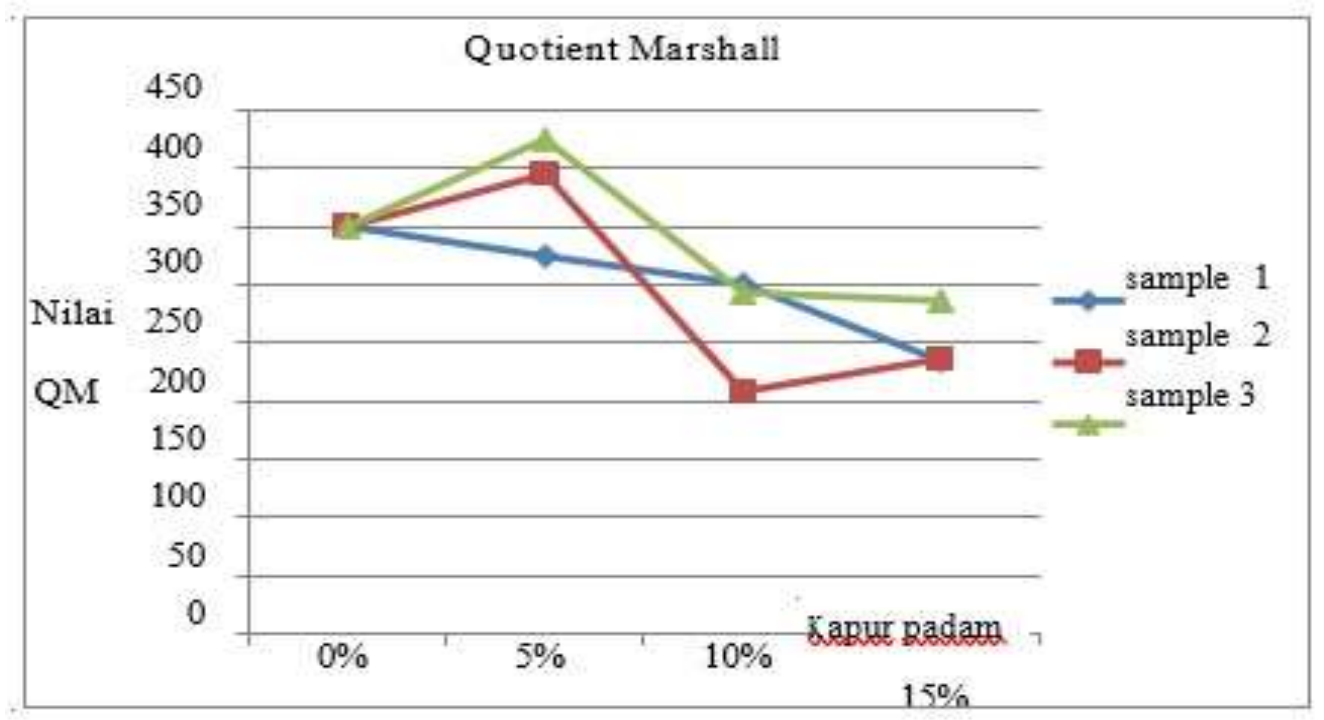

Grafik 5. Quotient Marshall Kapur Padam

Sumber : Analisa Perhitungan

\section{KESIMPULAN DAN SARAN}

\subsection{Kesimpulan}

Dari hasil perhitungan, maka dapat disimpulkan sebagai berikut :

1. Nilai stabilitas masing-masing penurunannya dengan pemambahan kapur padam yaitu $5 \%$ sebesar $778 \mathrm{Kg}, 10 \%$ sebesar $645 \mathrm{Kg}, 15 \%$ sebesar $534 \mathrm{Kg}$.

2. Hasil volume rongga udara terhadap campuran (VIM) dengan kadar 5\%, $10 \%$ dan $15 \%$ yaitu $8.17 \%, 7.51 \%$, dan $6.85 \%$.

3. Hasil volume pori antara butir agregat (VMA) dengan kadar 5\%, 10\% dan 15\% yaitu antara lain $19.87 \%, 18.55 \%$, dan $17.73 \%$.

4. Hasil volume pori antara butir agregat yang terisi aspal (VFB) dengan kadar 5\%, 10\% dan $15 \%$ yaitu antara lain $58.88 \%, 56.61 \%$, dan $54.35 \%$.

5. Hasil nilai Marshall Quotient (MQ) dengan kadar 5\%, 10\% dan 15\% Marshall Quotient (MQ) yaitu antara lain $297 \mathrm{Kg} / \mathrm{mm}, 230 \mathrm{Kg} / \mathrm{mm}$, dan $198 \mathrm{Kg} / \mathrm{mm}$.

\subsection{Saran}

Saran yang bisa diberikan penulis adalah perlu adanya perhatian lebih lagi dari pemerintah setempat untuk memaksimalkan sumberdaya terbaharukan yang ada didaerahnya, sehingga bisa mengurangi penggunaan bahan dari luar daerah.

\section{UCAPAN TERIMAKASIH}

Dalam penyusunan artikel ini, penulis ucapkan terimakasih kepada dosen pembimbing dan Universitas Kadiri. Penulis berharap agar artikel ini dapat bermanfaat bagi pembaca. 


\section{DAFTAR PUSTAKA}

[1] S. S. T. A. Sta, D. Satriawan, and E. Rita, "LENTUR DI RUAS JALAN LUBUK SELASIH - SURIAN KABUPATEN THE MAIN ROAD GEOMETRY PLAN AND FLEXIBLE AT SPACE BETWEEN LUBUK SELASIH - SURIAN SOLOK REGENCY ( STA $23+, " 2013$.

[2] B. C. Fambella, R. Sulaksitaningrum, M. Z. Arifin, and H. Bowoputro, "Evaluasi dan Perencanaan Geometrik Jaringan Jalan di Dalam Universitas Brawijaya Malang,” J. Mhs. Jur. Tek. Sipil, vol. 1, no. 3, p. pp-1146, 2015.

[3] E. Gardjito, A. I. Candra, and Y. Cahyo, "Pengaruh Penambahan Batu Karang Sebagai Substitusi Agregat Halus Dalam Pembuatan Paving Block," UKaRsT, vol. 2, no. 1, p. 35, 2018, doi: 10.30737/ukarst.v2i1.374.

[4] S. Silvia, "Dasar-dasar Perencanaan Geometrik Jalan," Penerbit Nova. Bandung, 1994.

[5] A. R. Fauzi, A. D. Limantara, and Y. Cahyo, "PEMANFAATAN LIMBAH HASIL PEMBUATAN ANYAMAN BERBAHAN BAMBU SEBAGAI CAMPURAN STANDARD MIXDESIGN PAVING BLOCK," Jurmateks, vol. 1, no. 1, pp. 137-147, 2018.

[6] B. Marga, "Tata Cara Perencanaan Geometrik Jalan Antar Kota," Direktorat Pembin. Jalan Kota. Jakarta, 1997.

[7] D. P. U. SKBI-2.3. 26. 1987, UDC: 625.73 (02), "Petunjuk Perencanaan Komponen Tebal Perkerasan Lentur Jalan Raya Dengan Metode Analisa Jalan,” Peratur. Perenc. Geom. Jalan Raya, no. 13, 1970.

[8] D. Pribadi, M. J. Paransa, T. K. Sendow, and L. J. Undap, "Tinjauan geometrik jalan pada ruas Jalan Airmadidi-Tondano menggunakan alat bantu GPS," J. Sipil Statik, vol. 1, no. 7, 2013.

[9] D. D. B. Marga, "Tata Cara Perencanaan Geometrik Jalan Antar Kota," Dirjen DPU Bina Marga, 1997.

[10] Pusjata - Balitbang PU, "Metode Pengujian Berat Jenis Dan Penyerapan Airagregat Kasar," Sni 03-1969-1990, pp. 2-5, 1990.

[11] D. P. Umum, “SNI 03-1969-1990," Metod. Penguji. Berat Jenis Dan Penyerapan Air Agreg. Kasar, 1990.

[12] V. Ayan, M. C. Limbachiya, J. R. Omer, and S. M. N. Azadani, "Compaction assessment of recycled aggregates for use in unbound subbase application," J. Civ. Eng. Manag., vol. 20, no. 2, pp. 169-174, 2014, doi: 10.3846/13923730.2013.801882.

[13] G. Sugiyanto, "Marshall test characteristics of asphalt concrete mixture with scrapped tire rubber as a fine aggregate," J. Teknol., vol. 79, no. 2, pp. 55-64, 2017, doi: 
10.11113/jt.v79.6965.

[14] Departemen Pekerjaan Umum, "Petunjuk Perencanaan Tebal Perkerasan Lentur Jalan Raya Dengan Metode Analisa Komponen," 1987.

[15] R. Ananda and D. P. Retno, "Evaluasi Perencanaan Geometrik Pada Ruas Jalan Lubuk Sakat-Teluk Petai Pada km 2-km 4, 8 Kabupaten Kampar,” J. Saintis, vol. 14, no. 2, pp. 54-65, 2014.

[16] S. L. Hendarsin, "Perencanaan Teknik Jalan raya," Politek. Negeri Bandung, 2000.

[17] A. Badrujaman, "Perencanaan Geometrik Jalan dan Anggaran Biaya Ruas Jalan Cempaka-Wanaraja Kecamatan Garut Kota,” J. Konstr., vol. 14, no. 1, 2016.

[18] J. McNulty, "PEMANFAATAN LIMBAH BETON SEBAGAI PENGGANTI AGREGAT KASAR PADA CAMPURAN ASPHALT CONCRETE-WEARING COURSE GRADASI KASAR Arys,” vol. 66, no. 1997, pp. 37-39, 2013.

[19] A. F. Setya Budi, F. N. Liem, and K. Alokabel, "STUDI KOMPARASI PENGARUH VARIASI PENGGUNAAN NILAI KONSTANTA ASPAL RENCANA TERHADAP NILAI STABILITAS PADA CAMPURAN ASPAL BETON (HRS-WC) TERHADAP KARAKTERISTIK UJI MARSHALL,” JUTEKS - J. Tek. Sipil, 2017, doi: 10.32511/juteks.v2i1.124.

[20] R. T. Bethary and M. F. Pradana, "PERENCANAAN GEOMETRIK JALAN ALTERNATIF PALIMA-CURUG ((Studi Kasus: Kota Serang),” J. Fondasi, vol. 5, no. 2, 2016.

[21] Dinas Pekerjaan Umum Direktorat Jenderal Bina Marga, Manual Perkerasan Jalan Dengan Alat Benkelmen Beam No. 01/MN/BM/83. Jakarta: Yayasan Badan Penerbit PU, 1983.

[22] Departemen Pekerjaan Umum, Metode AASTHO 1972. Jakarta: Yayasan Badan Penerbit PU, 1972.

[23] H. Fithra, "PENGARUH JUMLAH TUMBUKAN PADA CAMPURAN ASPHALT CONCRETE WEARING COURSE (AC-WC) TAMBAHAN LATEKS TERHADAP SIFAT MARSHALL," Teras J., 2017. 